\title{
Hubungan Fungsi Kognitif Berdasarkan Skor MMSE dengan Hasil CT Scan Kepala Pasien Lansia
}

\author{
Damiana Nirmala Mukti Handayani ${ }^{1}$, Rachmi Fauziah Rahayu ${ }^{2}$, \\ Nanang Wiyono ${ }^{3}$ \\ 1. Fakultas Kedokteran Universitas Sebelas Maret \\ 2. Bagian Radiologi RSUD Dr. Moewardi \\ 3. Laboratorium Anatomi Fakultas Kedokteran Universitas Sebelas Maret
}

Korespondensi : damiananirmala@student.uns.ac.id

\begin{abstract}
ABSTRAK
Pendahuluan: Penurunan fungsi kognitif merupakan penyebab utama disabilitas dan ketergantungan akan perawatan lansia. Skrining dengan instrumen mini-mental state examination (MMSE) memungkinkan kita untuk menilai fungsi kognitif seseorang secara kasar. Sementara itu, pemeriksaan imaging dapat menunjukkan perubahan struktural otak yang sering dikaitkan dengan berbagai gangguan fungsi tubuh dan dapat menjadi prediktor munculnya demensia. Penelitian mengenai topik ini masih jarang dilakukan di Indonesia. Oleh karena itu, penelitian ini dilaksanakan untuk mempelajari hubungan antara hasil penilaian fungsi kognitif dengan MMSE dan hasil computed tomography (CT) scan kepala pasien lansia, yang distandarisasi dengan kriteria penilaian skala global cortical atrophy (GCA).

Metode: Penelitian ini merupakan sebuah studi deskriptif analitik. Populasi yang diteliti merupakan pasien yang berusia $\geq 60$ tahun, menjalani pemeriksaan CT scan kepala pada tahun 2021, dan mampu menjalani MMSE selama periode pengambilan data penelitian. Sampel diambil dengan the rule of thumb sebanyak 30 orang. Analisis data dilakukan dengan uji korelasi rank Spearman.

Hasil: Penelitian ini diikuti oleh 18 pasien perempuan dan 12 pasien laki-laki. Sebagian besar pasien memiliki fungsi kognitif yang normal dengan rata-rata skor MMSE 26 $( \pm 3,42)$ dan skala GCA $1-2$. Terdapat korelasi negatif yang signifikan secara statistik $(\mathrm{r}=-0,546 / \mathrm{p}<0,002)$ antara fungsi kognitif berdasarkan skor MMSE dengan hasil pemeriksaan CT scan kepala pasien lansia.

Kesimpulan: Terdapat hubungan negatif berkekuatan moderat antara fungsi kognitif berdasarkan skor MMSE dengan hasil pemeriksaan CT scan kepala pasien lansia.
\end{abstract}

Kata Kunci: lansia; fungsi kognitif; MMSE; skala GCA; CT scan

ABSTRACT

Introduction: Declined cognitive function is a leading cause of disability and dependence on elderly care. The mini-mental state examination (MMSE) screening enables us to assess a person's cognitive function roughly. Meanwhile, imaging examinations can show the structural changes of the brain that are often associated with various disorders of body function and can be predictors of the emergence of dementia. Research on this topic is still done infrequently in Indonesia. Therefore, this research aims to study the correlation between the cognitive function based on MMSE score and the results of head CT scans of elderly patients, standardized with the global cortical atrophy (GCA) scale.

Methods: This research is an analytical descriptive study. The population studied were patients aged $\geq 60$ years, underwent a head CT scan in 2021 and were able to undergo MMSE during the data collection period. The sample was taken using the rule of thumb for as many as 30 individuals. It was then analyzed using the Spearman rank correlation test.

SMART MEDICAL JOURNAL (2021) Vol. 4 No. 3. eISSN : 2621-0916

This work is licensed under a Creative Commons Attribution (CC BY 4.0) licence 
Results: This study observed 18 female and 12 male patients. Most of the patients had normal cognitive function with a mean MMSE score of $26( \pm 3.42)$ and a GCA scale of 1 2. There was a statistically significant negative correlation $(r=-0.546 / p<0.002)$ between cognitive function based on the MMSE score and the results of head CT scans of the elderly patients.

Conclusion: There is a moderate negative correlation between cognitive function based on the MMSE scores and the results of the head CT scans of elderly patients.

Keywords: elderly; cognitive function; MMSE; GCA scale; CT scan

\section{PENDAHULUAN}

Penyebab utama disabilitas dan ketergantungan akan perawatan lansia adalah penurunan fungsi kognitif ${ }^{1}$. Penurunan fungsi kognitif tidak hanya merugikan orang yang mengalaminya, tetapi juga menjadi tantangan bagi keluarga, masyarakat, dan negara ${ }^{2}$. Gangguan ini berdampak pada kualitas hidup manusia karena berkaitan dengan kemandirian seseorang dalam beraktivitas sehari-hari dan berinteraksi sosial ${ }^{3}$.

WHO menyebutkan bahwa 5-8\% dari orang-orang berusia di atas 60 tahun mengalami penurunan fungsi kognitif berupa demensia dan sebagian besar di antaranya tinggal di wilayah dengan pendapatan menengah ke bawah ${ }^{4}$. Penderita demensia di Indonesia diperkirakan berjumlah 1,2 juta orang di Indonesia pada tahun 2016 dan cenderung meningkat dari tahun ke tahun 5 . Belum ada data mengenai populasi penderita demensia di Jawa Tengah, tetapi peningkatan angka harapan hidup meningkatkan jumlah populasi lansia yang berisiko menderita demensia $^{6,7}$.

Tidak hanya lansia, sebanyak 9\% dari kasus demensia diderita oleh orang yang berusia kurang dari 65 tahun $^{4}$. Penyakit Alzheimer, dapat mulai berkembang dalam diri seseorang sejak 20 tahun sebelum munculnya gejala ${ }^{8}$.

Meskipun gejala penurunan fungsi kognitif banyak dialami oleh lansia, gangguan ini bukanlah sesuatu yang dapat dianggap wajar sehingga bisa diabaikan". Penurunan fungsi kognitif merupakan gangguan yang progresif dan kompleks sehingga belum ada obat yang dapat menyembuhkannya ${ }^{10}$. Tata laksana yang ada saat ini lebih difokuskan untuk menyembuhkan penyakit yang mendasari gangguan tersebut atau mengatasi gejala yang muncul ${ }^{4}$.

Pencegahan dan deteksi adanya penurunan fungsi kognitif perlu dilakukan sedini mungkin supaya pasien mendapatkan informasi yang cukup, lebih banyak pilihan perawatan, dan dukungan untuk mengontrol kondisi mereka serta menjaga kualitas hidupnya lebih lama ${ }^{8}$. Pasien dan keluarganya dapat mulai membuat perencanaan ketika pasien masih memiliki kapasitas kognitif yang cukup. Selain itu, dengan memahami kondisi demensia pada tahap yang lebih awal, keluarga pasien memiliki waktu yang lebih panjang untuk beradaptasi dengan perubahan yang mungkin terjadi dan menyiapkan diri baik secara fisik maupun psikologis ${ }^{11}$.

Fungsi kognitif seseorang dapat dipengaruhi oleh banyak faktor, misalnya usia dan kondisi kesehatan seseorang ${ }^{12}$. Usia berpengaruh terhadap perubahan struktur otak $^{13}$. Perubahan struktur otak berupa atrofi dapat dikaitkan dengan demensia, kejang, dan afasia ${ }^{14}$. Perubahan pada otak terkadang juga ditemukan pada orang yang memiliki fungsi kognitif baik dan hal ini dapat menjadi prediktor munculnya demensia pada beberapa dekade yang akan datang ${ }^{13}$. Pemeriksaan fungsi kognitif dengan instrumen skrining seperti mini mental state examination (MMSE) saja kurang akurat untuk menilai fungsi kognitif seseorang ${ }^{15}$. Pemeriksaan dengan pencitraan memungkinkan kita untuk 
mengetahui perubahan struktural otak yang sering dikaitkan dengan berbagai gangguan fungsi tubuh.

Penelitian ini terispirasi dari beberapa penelitian terdahulu dengan topik atrofi otak dan fungsi kognitif ${ }^{15,} 25,26$. Perbedaannya dengan penelitian sebelumnya dapat dilihat dari lokasi dan subjek penelitian, instrumen penilaian fungsi kognitif, serta modalitas dan parameter yang digunakan untuk menilai atrofi otak. Di Indonesia, topik ini masih jarang diteliti. Oleh karena itu, penelitian ini dilaksanakan untuk mempelajari hubungan antara hasil penilaian fungsi kognitif dengan MMSE dan hasil CT scan kepala pasien lansia, yang distandarisasi dengan kriteria penilaian skala global cortical atrophy (GCA).

\section{METODE}

Penelitian ini merupakan sebuah studi deskriptif analitik. Data MMSE merupakan data primer yang diperoleh langsung dari sumber datanya, sedangkan data lainnya merupakan data sekunder dari rekam medis elektronik ${ }^{16}$. Data diambil di Rumah Sakit Dr. Oen Solo Baru, Sukoharjo, Jawa Tengah, Indonesia dalam rentang waktu 1 Juli -31 Oktober 2021.

Populasi yang diteliti merupakan pasien berusia $\geq 60$ tahun yang menjalani pemeriksaan CT scan kepala di unit Radiologi pada tahun 2021 dan mampu menjalani pemeriksaan MMSE selama periode pengambilan data penelitian. Dalam penelitian ini, pemeriksaan CT scan hanya dilakukan jika ada indikasi medis untuk mengurangi paparan radiasi yang tidak diperlukan. Kriteria eksklusi yang digunakan, yaitu riwayat penyakit tumor otak, hidrosefalus, trauma, infeksi kepala, dan gangguan otak organik lainnya, riwayat penyalahgunaan substansi dan alkohol, riwayat gangguan kejiwaan seperti depresi dan skizofrenia, dan riwayat terapi yang dapat menyebabkan penurunan fungsi kognitif.

Karena keterbatasan waktu dan sumber daya manusia, sampel didapatkan dengan the rule of thumb, yaitu sebanyak 30 sampel.

Hasil CT scan kepala pada penelitian ini dinilai berdasarkan skala GCA oleh dokter spesialis radiologi. Skala GCA merupakan skor rata-rata untuk atrofi kortikal di seluruh cerebrum, meliputi dilatasi sulci (frontal, parieto-occipital, dan temporal dextra dan sinistra), serta dilatasi ventrikel (frontal, parieto-occipital dan temporal dextra dan sinistra, dan third ventricle $)^{17}$. Pemeriksaan skala GCA dilakukan dengan CT scan. Skor berkisar antara 0-3 berdasarkan pelebaran ventrikel atau hilangnya volume gyri ${ }^{18}$.

Fungsi kognitif diukur dengan instrumen MMSE yang memiliki skor 0-30. Skor untuk fungsi kognitif yang dapat dianggap normal adalah 25-30, sedangkan demensia ringan 20-24, demensia sedang 1319, dan demensia berat 0-12 ${ }^{19}$.

Pengolahan data deskriptif (usia, jenis kelamin, pekerjaan, klinis, dan cella media index/CMI) dikerjakan dengan Microsoft Excel. Karena variabel-variabel yang diteliti merupakan data kategorik dengan skala ordinal, kekuatan dan jenis hubungan antar variabel diuji dengan uji korelasi Rank Spearman dengan Statistical Product and Service Solution (SPSS) 22.0 for Windows.

Penelitian ini telah dinyatakan layak etik oleh Komisi Etik Penelitian Kesehatan RSUD Dr. Moewardi dengan nomor surat 410/IV/HREC/2021.

\section{HASIL}

\section{Data Hasil Penelitian}

Pasien lansia yang menjadi sampel dalam penelitian ini sebagian besar termasuk dalam kelompok usia 60-66 tahun, yaitu sebanyak 15 orang (50\%). Sementara itu, perbandingan jenis kelamin laki-laki dan perempuan adalah 2:3. Para pasien memiliki 
pekerjaan yang bervariasi, mayoritas ibu rumah tangga. Selain itu, berdasarkan riwayat medisnya, hampir semua pasien dalam studi ini memiliki riwayat stroke.

Hasil pemeriksaan CT scan menunjukkan bahwa kebanyakan sampel, yaitu sebanyak 23 orang $(76,67 \%)$, memiliki CMI dalam kisaran 4,0-3,6. Pemeriksaan ini juga menemukan adanya chronic infarct di bagian otak yang bervariasi pada orang dengan riwayat stroke.

Rekapitulasi data hasil penelitian dapat dilihat pada tabel dan ulasan berikut ini.

Tabel 1. Distribusi Sampel Berdasarkan Kelompok Usia, Jenis Kelamin, Pekerjaan, Klinis, dan CMI

\begin{tabular}{|c|c|c|}
\hline Demografi Pasien & $\begin{array}{l}\text { Frekuensi } \\
\quad \mathrm{N}(\%)\end{array}$ & $\begin{array}{c}\text { Mean } \pm \\
\text { SD }\end{array}$ \\
\hline Usia & & $67,43 \pm$ \\
\hline 60-66 tahun & $15(50)$ & 5,68 \\
\hline $67-73$ tahun & $10(33,33)$ & \\
\hline 74-80 tahun & $5(16,67)$ & \\
\hline \multicolumn{3}{|l|}{ Jenis kelamin } \\
\hline Laki-laki & $12(40)$ & \\
\hline Perempuan & $18(60)$ & \\
\hline \multicolumn{3}{|l|}{ Pekerjaan } \\
\hline Ibu rumah tangga & $10(33,33)$ & \\
\hline TNI/POLRI & $2(6,67)$ & \\
\hline Guru & $5(16,67)$ & \\
\hline Karyawan & $5(16,67)$ & \\
\hline Petani & $3(10)$ & \\
\hline Buruh & $3(10)$ & \\
\hline Tenaga kesehatan & $2(6,67)$ & \\
\hline \multicolumn{3}{|l|}{ Klinis } \\
\hline Penyakit & $1(3,33)$ & \\
\hline Parkinson & & \\
\hline Demensia & $2(6,67)$ & \\
\hline Stroke & $26(86,67)$ & \\
\hline Convulsion & $1(3,33)$ & \\
\hline Cephalgia & $8(26,67)$ & \\
\hline Vertigo & $1(3,33)$ & \\
\hline Penyakit jantung & $2(6,67)$ & \\
\hline $\begin{array}{l}\text { Penyakit ginjal } \\
\text { kronis }\end{array}$ & $1(3,33)$ & \\
\hline Hipertensi & $17(56,67)$ & \\
\hline $\begin{array}{l}\text { Penyakit paru } \\
\text { obstruktif kronis }\end{array}$ & $1(3,33)$ & \\
\hline Gastritis & $6(20)$ & \\
\hline
\end{tabular}

\begin{tabular}{lcc} 
Hiperlipidemia & $1(3,33)$ & \\
Diabetes Mellitus & $8(26,67)$ & \\
tipe 2 & & \\
$\quad$ Post COVID-19 & $6(20)$ & \\
CMI & & $3,73 \pm$ \\
$\geq 4,1$ & $1(3,33)$ & 0,20 \\
$4,0-3,6$ & $23(76,67)$ & \\
$3,5-3,0$ & $6(20)$ & \\
$\leq 2,9$ & $0(0)$ & \\
\hline
\end{tabular}

Rentang skor MMSE yang didapatkan oleh pasien lansia yang menjadi sampel berkisar antara 12-30. Hanya terdapat satu partisipan yang memperoleh skor sempurna 30 dan satu partisipan mendapatkan skor 12 .

Tabel 2. Perolehan Skor MMSE Sampel

\begin{tabular}{cccc}
\hline & Min. & Maks. & Mean \pm SD \\
\hline Skor MMSE & 12 & 30 & $26 \pm 3,42$ \\
\hline
\end{tabular}

Distribusi sampel berdasarkan fungsi kognitifnya dapat dilihat lebih terperinci pada tabel di bawah ini.

Tabel 3. Distribusi Sampel Berdasarkan Fungsi Kognitif

\begin{tabular}{lcc}
\hline \multicolumn{1}{c}{$\begin{array}{c}\text { Fungsi kognitif } \\
\text { berdasarkan skor MMSE }\end{array}$} & $\begin{array}{c}\text { Frekuensi } \\
(\mathrm{n})\end{array}$ & $\%$ \\
\hline Normal (25-30) & 26 & 86,67 \\
Demensia ringan (20-24) & 3 & 10 \\
Demensia sedang (13-19) & 0 & 0 \\
Demensia berat (0-12) & 1 & 3,33 \\
Total & 30 & 100 \\
\hline
\end{tabular}

Sebagian besar pasien yang diteliti memiliki fungsi kognitif yang tergolong normal walaupun skor MMSE tidak mencapai angka sempurna. Terdapat 3 pasien $(10 \%)$ yang mengalami demensia ringan dan 1 pasien $(3,33 \%)$ yang mengalami demensia berat.

Tabel 4. Distribusi Sampel Berdasarkan Skala

\begin{tabular}{lcc}
\multicolumn{3}{c}{ GCA } \\
\hline Skala GCA & Frekuensi (n) & $\%$ \\
\hline 0 & 0 & 0 \\
1 & 24 & 80 \\
2 & 6 & 20 \\
3 & 0 & 0 \\
Total & 30 & 100 \\
\hline
\end{tabular}


Seluruh sampel menunjukkan adanya atrofi otak berdasarkan pemeriksaan CT scan dengan skala GCA. Sebanyak 24 sampel (80\%) menunjukkan skala GCA 1 dan sisanya, yaitu sebanyak 6 sampel (20\%), menunjukkan skala GCA 2.

\section{Data Hasil Analisis}

Data yang telah terkumpul kemudian dianalisis menggunakan program SPSS 22.0 for Windows dengan uji korelasi rank Spearman untuk menguji hubungan antara fungsi kognitif dan skala GCA.

Tabel 5. Tabulasi Silang Fungsi Kognitif dan Skala GCA

\begin{tabular}{|c|c|c|c|c|c|}
\hline & & \multicolumn{3}{|c|}{ Fungsi Kognitif } & \multirow[b]{2}{*}{ 吾 } \\
\hline & & $\begin{array}{l}\bar{Z} \\
\tilde{\Xi} \\
Z \\
Z\end{array}$ & 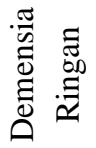 & 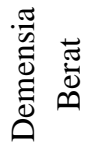 & \\
\hline Skala & 1 & 23 & 1 & 0 & 24 \\
\hline GCA & 2 & 3 & 2 & 1 & 6 \\
\hline Total & & 26 & 3 & 1 & 30 \\
\hline
\end{tabular}

Dari tabel di atas, dapat dilihat bahwa sebagian besar sampel yang fungsi kognitifnya tergolong normal menunjukkan skala GCA 1. Sementara itu, sampel yang mendapatkan skala GCA 2, memiliki fungsi kognitif yang bervariasi, yaitu normal (3 orang), demensia ringan (2 orang), dan demensia berat (1 orang).

Tabel 6. Uji Korelasi Spearman Fungsi Kognitif dengan Skala GCA

\begin{tabular}{ccc}
\hline & \multicolumn{2}{c}{ Fungsi Kognitif berdasarkan skor } \\
& \multicolumn{2}{c}{ MMSE } \\
\cline { 2 - 3 } & Koefisien Korelasi (r) & $\mathrm{p}$ \\
\hline Skala & $-0,546$ & 0,002 \\
GCA & & \\
\hline
\end{tabular}

Berdasarkan hasil uji korelasi Spearman dapat disimpulkan bahwa terdapat korelasi negatif yang signifikan secara statistik $(\mathrm{p}<0,01)$ antara fungsi kognitif berdasarkan skor MMSE dengan hasil pemeriksaan CT scan kepala pasien lansia. Menurut the rule of thumb $b^{20}$ koefisien korelasi $-0,546$ menunjukkan bahwa kekuatan korelasi tersebut moderat.

\section{PEMBAHASAN}

\section{Pembahasan Hasil}

Pasien yang menjadi partisipan penelitian ini berusia 60-80 tahun. Rerata usia partisipan dalam penelitian ini adalah 67,43 $( \pm 5,68)$, cenderung lebih muda daripada penelitian lainnya $^{15}, 25$. Sebanyak 18 pasien berjenis kelamin perempuan dan 10 di antaranya merupakan ibu rumah tangga. Dua per tiga dari pasien yang berpartisipasi bekerja di berbagai bidang, seperti tenaga kesehatan, anggota TNI/POLRI, guru, karyawan, petani, dan buruh.

Berdasarkan keterangan klinisnya, lebih dari $80 \%$ pasien memiliki riwayat stroke. Stroke merupakan penyebab penurunan fungsi kognitif, yaitu demensia vaskular. Hal ini terjadi karena adanya sumbatan maupun kerusakan pada pembuluh darah otak menimbulkan kematian jaringan dan perdarahan yang menghambat transportasi oksigen dan nutrien dari darah untuk sel-sel otak $^{21}$. Penurunan fungsi kognitif yang terjadi dipengaruhi oleh lokasi, jumlah, dan ukuran lesi infark yang ada ${ }^{8}$.

Riwayat penyakit yang paling banyak ditemukan setelah stroke dalam penelitian ini adalah hipertensi. Hipertensi merupakan salah satu faktor risiko dari berbagai penyakit, seperti jantung, ginjal, dan stroke. Penyakit hipertensi yang tidak diterapi berhubungan dengan kejadian atrofi otak dan penurunan fungsi kognitif ${ }^{26}$.

Selain itu, penelitian ini juga menemukan riwayat penyakit lain pada partisipan, yaitu cephalgia, diabetes mellitus tipe 2, penyakit jantung, penyakit ginjal, penyakit paru obstruktif kronis, gastritis, penyakit Parkinson, riwayat konvulsi, vertigo, dan hiperlipidemia. Berbagai penelitian 
menyebutkan bahwa kondisi-kondisi tersebut meningkatkan kemungkinan terjadinya demensia dan atrofi otak ${ }^{8,9}$.

Rata-rata CMI pasien dalam penelitian ini adalah 3,73 dengan standar deviasi 0,20 . Hal ini menunjukkan adanya pelebaran ventrikel ringan ${ }^{22}$. Penelitian oleh Chrzan et al. pada tahun 2019 melaporkan bahwa ratarata CMI pada kelompok usia 100-106 tahun lebih rendah secara signifikan daripada kelompok usia 70-79 tahun (4.32 dan 5.32 $)^{28}$. Penelitian lain dengan cella media ratio (CMR) menunjukkan bahwa CMR memiliki korelasi positif terhadap usia ${ }^{23}$. Selain itu, CMR juga menunjukkan hubungan yang bermakna dengan diameter kepala, baik anteroposterior maupun transversal ${ }^{24}$. CMR membandingkan diameter paling sempit dari dinding luar ventrikel lateralis dengan diameter dalam os cranium di garis yang sama $^{23,}{ }^{24}$. Baik CMI maupun CMR bermanfaat pada diagnosis hidrosefalus obstruktif $^{23}$.

Data penelitian ini menunjukkan bahwa sebagian besar pasien memiliki fungsi kognitif yang normal. Rata-rata skor MMSE dari seluruh pasien adalah 26 dengan standar deviasi 3,42. Menurut Buku Manual Psikiatri Skills Lab FK UNS, angka ini masih tergolong normal ${ }^{19}$. Rerata ini cenderung lebih tinggi dibanding penelitian oleh Al-Janabi et al. pada tahun 2018 yang diikuti 325 partisipan dengan rerata MMSE $23.2( \pm 7.8)$.

Jika ditinjau dari skala GCA, mayoritas pasien menunjukkan atrofi otak ringan dan sebanyak enam orang mengalami atrofi otak sedang. Pada lansia yang normal, atrofi otak menurut skala GCA bertambah 0,5\%, sedangkan pada penderita penyakit Alzheimer bisa sampai $1,3 \%$ setiap tahunnya ${ }^{25}$.

Gambaran CT scan kepala dengan berbagai skala GCA dapat dilihat di bawah ini. Pada gambar 1 kiri, skala GCA 0 didapatkan pada pasien wanita berusia 21 tahun. Gambar 1 kanan merupakan partisipan dari penelitian ini, yaitu seorang wanita berusia 69 tahun dengan skala GCA 1, sedangkan gambar 2 kiri merupakan partisipan pria berusia 63 tahun dengan skala GCA 2. Gambar 2 tengah dan kanan merupakan gambar CT scan otak dari seorang pasien dengan skala GCA 3.

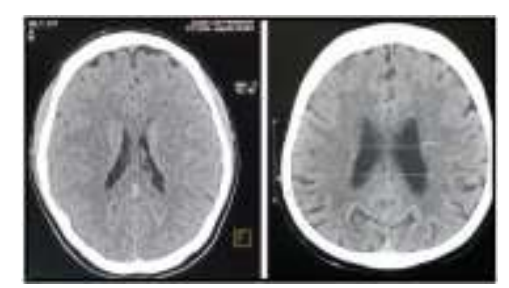

Gambar 1. CT Scan Kepala dengan Skala GCA 0 dan 1

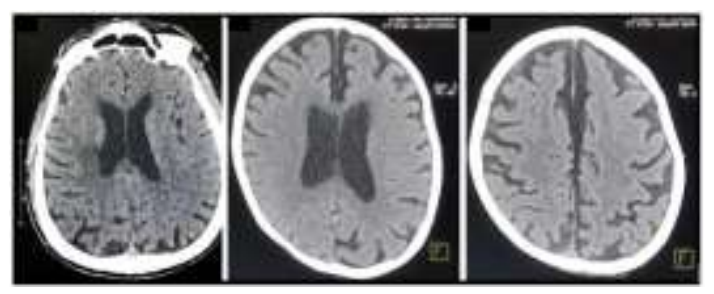

Gambar 2. Atrofi Sedang-Berat pada Skala GCA 2 dan 3

Fungsi kognitif berkaitan dengan kemampuan seseorang untuk memusatkan perhatian, belajar, berpikir, berbahasa, memersepsikan sesuatu, membuat pertimbangan dan mengambil keputusan, memecahkan masalah, serta mengingat ${ }^{29}$. Setiap domain fungsi kognitif dikontrol oleh beberapa bagian otak yang berbeda melalui proses yang kompleks. Lobus frontalis di bagian anterior memiliki fungsi memori prospektif (mengingat rencana), bahasa (menyampaikan ide, berbicara), kepribadian, fungsi eksekutif (membuat pertimbangan dan membuat keputusan), mempelajari sesuatu, menciptakan ide kreatif, dan kontrol pergerakan bagian tubuh kontralateral ${ }^{30}$. Di belakangnya terdapat lobus parietalis yang terutama mempunyai fungsi sensori. Lobus temporalis dan occipitalis berperan dalam persepsi auditori dan visual ${ }^{30}$. Selain itu, struktur pada lobus temporalis, yaitu hippocampus, entorhinal, perirhinal, dan parahippocampal cortex, berhubungan 
dengan fungsi memori deklaratif yang terdiri atas memori semantik (pengetahuan umum), memori rekognisi (mengenali sesuatu melalui rekoleksi atau familiaritas), dan memori episodik (mengingat kembali suatu hal) ${ }^{30}$.

Hal yang mendasari terbentuknya fungsi kognitif adalah komunikasi antarneuron. Atrofi otak berarti penyusutan otak akibat hilangnya sel-sel neuron dan koneksi antarneuron ${ }^{14}$. Pada derajat tertentu, atrofi otak akan mengganggu komunikasi antarneuron yang menyebabkan penurunan fungsi kognitif.

Penelitian mengenai hubungan fungsi kognitif berdasarkan skor MMSE dengan hasil CT scan kepala pasien lansia ini menunjukkan hubungan negatif yang signifikan berkekuatan moderat. Hubungan negatif yang dimaksud adalah semakin buruk fungsi kognitif pasien (skor MMSE makin rendah), maka semakin parah kondisi atrofi otaknya (skala GCA semakin tinggi). Hal ini sejalan dengan penelitian yang menyebutkan bahwa peluang atrofi otak sedang-berat menurut skala GCA menurun 4,9\% dengan setiap peningkatan skor MMSE sebesar 1 $\operatorname{poin}^{25}$. Penelitian serupa yang dilakukan dengan instrumen Montreal Cognitive Assessment (MoCA) juga menyatakan bahwa skor MoCA berhubungan dengan keparahan skala GCA ${ }^{15}$.

Berkebalikan dengan penelitian ini, penelitian Chrismanita et al. pada tahun 2015 menunjukkan bahwa skor MMSE tidak memiliki hubungan yang bermakna dengan skala GCA yang diperiksa dengan $\mathrm{MRI}^{26}$. Akan tetapi, skor MMSE memiliki hubungan negatif berkekuatan sedang dengan lesi white matter, sedangkan skala GCA berkorelasi dengan pemeriksaan fungsi kognitif lainnya, yaitu tes vigilance, trail making test $\mathrm{A}$, dan trail making test B. Hal ini menunjukkan bahwa atrofi pada cerebrum memiliki hubungan dengan penurunan fungsi kognitif, khususnya pada domain atensi dan fungsi eksekutif $^{26}$.

\section{Keterbatasan Penelitian dan Saran}

Penelitian ini memiliki keterbatasan dalam pengambilan data. Proses pengumpulan data sempat terhambat karena peningkatan penularan COVID-19 di Indonesia pada periode Juli-September 2021 menyebabkan penurunan jumlah pasien yang berkunjung ke rumah sakit. Selain itu, sebagian pasien yang menjalani CT scan kepala datang dalam kondisi yang tidak memungkinkan pemeriksaan MMSE. Oleh karena itu, pemeriksaan MMSE baru dilakukan ketika kondisi pasien sudah lebih stabil atau saat pasien kontrol.

Dari sisi instrumen, penelitian ini memiliki keterbatasan karena hanya menggunakan MMSE untuk menilai fungsi kognitif secara umum. Sebuah studi menemukan bahwa orang yang sehat masih memiliki kemungkinan mengalami penurunan fungsi kognitif, dan sebaliknya, orang-orang yang berada pada tahap awal demensia mungkin masih bisa mendapatkan skor MMSE melebihi batas normal ${ }^{27}$. Oleh karena itu, penelitian yang selanjutnya perlu menambahkan instrumen penilaian fungsi kognitif yang lebih spesifik, seperti tes atensi dengan Forward Digit Span, tes fungsi bahasa dengan Boston Naming Test, penilaian kemampuan fungsional dengan skor Activity Daily Living, dan sebagainya.

Sehubungan dengan distribusi sampel penelitian ini yang cenderung berkumpul pada kategori tertentu, studi di masa mendatang dianjurkan menggunakan lebih banyak sampel. Penerapan skrining faktor-faktor risiko yang berhubungan dengan penurunan fungsi kognitif dan atrofi otak juga dapat dilakukan untuk mengurangi bias. Selain itu, penelitian lanjutan dengan metode longitudinal direkomendasikan untuk melihat progresi atrofi otak dalam beberapa tahun. Sebagai tambahan, penggunaan lebih banyak parameter evaluasi otak, misalnya Medial Temporal Atrophy, Fazekas, serta skor Koedam, dan pemakaian modalitas 
neuroimaging lain, seperti MRI 3 Tesla atau Positron Emission Tomography (PET) scan, juga disarankan untuk mempelajari kondisi otak secara menyeluruh.

\section{KESIMPULAN}

Berdasarkan hasil penelitian dan pembahasan, peneliti menyimpulkan bahwa terdapat hubungan negatif berkekuatan moderat antara fungsi kognitif berdasarkan skor MMSE dengan hasil pemeriksaan CT scan kepala pasien lansia.

\section{UCAPAN TERIMA KASIH}

Peneliti mengucapkan terima kasih kepada Ida Prista Maryetty, dr., M. Kes, M. Sc, Sp. Rad yang telah memberikan kritik dan saran demi kesempurnaan penulisan artikel ini ini, direksi beserta staf bagian rekam medis, radiologi, dan poli spesialis RS Dr. Oen Solo Baru yang telah membantu proses pengambilan data penelitian, Martha Andri Hastuti Sulistyorini, dr., Sp. Rad selaku pemeriksa CT scan, dan para responden yang terlibat dalam penelitian ini.

\section{DAFTAR PUSTAKA}

1. Peracino A, Pecorelli S. The Epidemiology of Cognitive Impairment in the Aging Population: Implications for Hearing Loss. Audiology and Neurotology. 2016;21(Suppl. 1):3-9.

2. Kementerian Kesehatan Republik Indonesia (Kemenkes RI). Strategi Nasional Penanggulangan Penyakit Alzheimer dan Demensia Lainnya: Menuju Lanjut Usia Sehat dan Produktif. Jakarta: Kemenkes RI; 2015.

3. Sobral A, Araújo C, Sobral M. Mild cognitive impairment in the elderly Relationship between communication and functional capacity. Dementia \& Neuropsychologia. 2018;12(2):165-172.

4. World Health Organization (WHO). Dementia [Internet]. Who.int. 2020 [sitasi Januari 2021]. Diakses dari: https://www.who.int/news-room/factsheets/detail/dementia

5. Alzheimer Indonesia. Statistik tentang Demensia [Internet]. Alzi.or.id. 2019 [sitasi Januari 2021]. Diakses dari: https://alzi.or.id/statistik-tentang-demensia/

6. Ong $\mathrm{P}$, et al. Panduan Praktik Klinik Diagnosis dan Penatalaksanaan Demensia. Jakarta: Perhimpunan Dokter Spesialis Saraf Indonesia; 2015.

7. Badan Pusat Statistik (BPS). [IPG] Angka Harapan Hidup (AHH) Menurut Provinsi dan Jenis Kelamin, 2010-2018. [Internet]. Bps.go.id. 2019 [sitasi Februari 2021]. Diakses dari: https://www.bps.go.id/linkTableDinamis/vi ew/id/1114

8. Alzheimer's Association Report. 2020 Alzheimer's disease facts and figures. Alzheimer's and Dementia. 2020;16(3):391460.

9. Chairina N, Ahyar J. Selamatkan Otak, Kenali Gangguan Demensia (Pikun) Menjelang Lansia. 2019:1-8.

10. Centers for Disease Control and Prevention (CDC). What Is Dementia? [Internet]. Cdc.gov. 2019 [sitasi Januari 2021]. Diakses dari: https://www.cdc.gov/aging/dementia/index. html

11. Rasmussen J, Langerman H. Alzheimer's Disease - Why We Need Early Diagnosis. Degenerative Neurological and Neuromuscular Disease. 2019;9:123-130.

12. Molloy DW. Standardized Mini-Mental State Examination (SMMSE) | IHPA. American Journal of Psychiatry. 2014;14:102-105.

13. Harada C, Natelson Love M, Triebel K. Normal Cognitive Aging. Clinics in Geriatric Medicine. 2013;29(4):737-752.

14. National Institute of Neurological Disorders and Stroke (NINDS). Cerebral Atrophy Information Page [Internet]. Ninds.nih.gov. 2019 [sitasi Februari 2021]. Diakses dari: https://www.ninds.nih.gov/Disorders/AllDisorders/Cerebral-Atrophy-InformationPage 
15. Del Brutto O, Mera R, Zambrano $M$, Soriano F, Lama J. Global cortical atrophy (GCA) associates with worse performance in the Montreal Cognitive Assessment (MoCA). A population-based study in community-dwelling elders living in rural Ecuador. Archives of Gerontology and Geriatrics. 2015;60(1):206-209.

16. Masturoh I, Temesvari NA. Metodologi Penelitian Kesehatan. 1st ed. Jakarta: Badan Pengembangan dan Pemberdayaan Sumber Daya Manusia Kesehatan Kemenkes RI; 2018.

17. Di Muzio B, Weerakkody Y. Global cortical atrophy scale [Internet]. Radiopaedia.org. 2018 [sitasi Januari 2021]. Diakses dari: https://radiopaedia.org/articles/37584

18. Wahlund L, Westman E, van Westen D, Wallin A, Shams S, Cavallin L, dkk. Imaging biomarkers of dementia: recommended visual rating scales with teaching cases. Insights into Imaging. 2016;8(1):79-90.

19. Skills lab FK UNS. Modul Skills lab Psikiatri. Surakarta: Fakultas Kedokteran Universitas Sebelas Maret; 2020.

20. Mukaka MM. A Guide to Appropriate Use of Correlation Coefficient in Medical Research. Malawi Med J. 2012;24(3):69-71.

21. Vijayan M, Reddy P. Stroke, Vascular Dementia, and Alzheimer's Disease: Molecular Links. Journal of Alzheimer's Disease. 2016;54(2):427-443.

22. Goel A, Gaillard F. Cella media index [Internet]. Radiopaedia.org. 2021 [sitasi September 2021]. Diakses dari: https://radiopaedia.org/articles/cella-mediaindex

23. Kolsur N, P.M R, Shetty S, Kumar A. Morphometric Study of Ventricular Indices in Human Brain Using Computed Tomography Scans in Indian Population. International Journal of Anatomy and Research. 2018;6(3.2):5574-5580.

24. Patnaik P, Singh V, Singh S, Singh D. Lateral Ventricle Ratios Correlated to Diameters of Cerebrum - A Study on CT scans of Head. J Anat Sciences. 2014;22(2):5-11.

25. Al- Janabi O, Panuganti P, Abner E, Bahrani A, Murphy R, Bardach S, dkk. Global Cerebral Atrophy Detected by Routine Imaging: Relationship with Age, Hippocampal Atrophy, and White Matter Hyperintensities. Journal of Neuroimaging. 2018;28(3):301-306.

26. Chrismanita, Ong A, Rizal A. Hubungan Antara Kejadian Hipertensi dengan Performa Fungsi Kognisi dan Gambaran Magnetic Resonance Imaging Kepala. Neurona. 2015;32(2).

27. Votruba K, Persad C, Giordani B. Cognitive Deficits in Healthy Elderly Population With "Normal" Scores on the Mini-Mental State Examination. Journal of Geriatric Psychiatry and Neurology. 2016;29(3):126132.

28. Chrzan R, Gleń A, Bryll A, Urbanik A. Computed Tomography Assessment of Brain Atrophy in Centenarians. International Journal of Environmental Research and Public Health. 2019;16(19):3659.

29. Fisher GG, Chacon M, Chaffee D. Theories of Cognitive Aging and Work. Work Across the Lifespan. 2019;:17-45.

30. Jawabri KH, Sharma S. Physiology, Cerebral Cortex Functions. Treasure Island (FL): StatPearls Publishing [Internet]; 2020 [sitasi Februari 2021]. Diakses dari: https://www.ncbi.nlm.nih.gov/books/NBK5 38496/ 